\title{
A FORMAÇÃO DE PROFESSORES NA EDUCAÇÃO PROFISSIONAL E TECNOLÓGICA E A COMPLEXIDADE QUE ENVOLVE A PERMANÊNCIA E ÊXITO DOS ESTUDANTES
}

\author{
Rozieli Bovolini Silveira; Lizandra Falcão Gonçalves; Mariglei Severo Maraschin \\ Universidade Federal de Santa Maria; Instituto Federal de Educação, Ciência e Tecnologia Farroupilha \\ rozieli.silveira@iffarroupilha.edu.br; lizandra.goncalves@ufsm.edu.br; marigleism@hotmail.com \\ 10.15628/rbept.2017.5712 \\ Artigo submetido em mar/2017 e aceito em out/2017
}

\section{RESUMO}

Este artigo tem como objetivo compreender, a partir do Programa Permanência e Êxito (PPE), como se dá a formação continuada de professores no contexto da educação profissional e tecnológica. Para isso foi feita uma pesquisa documental na legislação no que se refere à formação continuada de professores, bem como uma busca contextualizada com produções acadêmicas, sobre o tema. A partir dessa construção foi possível observar que as políticas educacionais para a formação docente para a Educação Profissional e Tecnológica (EPT) ainda não são consistentes e duradouras, o novo Plano Nacional da Educação (PNE 20142024) e o Parecer CNE/CP 02/2015 homologado pelo Ministério da Educação (MEC) sinalizavam um avanço qualitativo para a formação continuada docente, porém com a última publicação do Ministério da Educação, por meio da Medida Provisória n. 746/2016, houve um retrocesso sobre a formação de professores para atuarem na EPT.

Palavras-Chaves: Educação Profissional e Tecnológica, formação docente, Programa Permanência e Êxito

\begin{abstract}
This article aims at understand, from the Permanence and Success Program (PPE), how the continuous training of teachers in the context of professional and technological education takes place. For this, a documentary research was done in the legislation regarding the continuous formation of teachers, as well as a contextualized search with academic productions, on the subject. From this construction it was possible to observe that the educational policies for teacher education for Vocational and Technological Education (EPT) are still not consistent and lasting, the new National Education Plan (PNE 2014-2024) and the CNE / CP 02 Opinion / 2015 approved by the Ministry of Education (MEC) signaled a qualitative advance for continuing teacher education, but with the latest publication of the Ministry of Education, through Provisional Measure n. 746/2016, there was a setback for teacher training to work at EPT.
\end{abstract}

KEYWORDS: Professional and Technological Education, formation teacher, Permanence and Success Program 


\section{APONTAMENTOS INICIAIS}

A Rede Federal de Educação Profissional e Tecnológica recebeu forte estímulo à expansão a partir do ano de 2003 com o governo do presidente Luís Inácio Lula da Silva. No final de 2008 foram criados 38 Institutos Federais de Educação, Ciência e Tecnologia, promulgada através da Lei n. 11.892 de 29 de dezembro deste mesmo ano.

Os institutos federais são constituídos por uma grande diversidade de saberes e fazeres. A realidade dessas instituições muitas vezes é permeada por dificuldades e desafios, principalmente em relação ao público do qual essa política educacional se propõe a atender. Um desses entraves é em relação a formação continuada de professores para suprir as demandas de evasão e retenção.

Este artigo versa sobre a formação continuada de professores na Educação Profissional e apresenta definições acerca do entendimento sobre formação continuada na legislação. Essa construção destaca a formação continuada de professores associada à evasão e retenção, que consta como proposta do Programa Permanência e Êxito desenvolvido em um Instituto Federal localizado na região sul do Brasil que é composto por 11 campi e a Reitoria

O artigo tem como objetivo geral compreender, a partir do programa permanência e êxito (PPE), como se dá a formação continuada de professores no contexto da educação profissional e tecnológica e como objetivos específicos, aprofundar o conhecimento sobre a práxis da formação de professores na Educação Profissional, refletir sobre as relações entre a formação de professores e a evasão e retenção e compreender os marcos legais da educação nacional no que se refere à formação continuada de professores também na Educação Profissional. Para atingir estes objetivos adotou-se a pesquisa qualitativa, com a análise documental.

\section{METODOLOGIA}

O presente estudo traz como metodologia, a pesquisa qualitativa, que será norteada e estruturada a partir da análise documental. Para isso foi analisada a legislação educacional brasileira no que se refere à formação continuada de professores, tais como as Diretrizes e Bases da Educação-Lei 9394/96 de 20 de dezembro de 2006, o Plano Nacional de Educação- Lei 13.005 de 20 de junho de 2014, o Parecer CNE/CP 02/2015, homologado pelo Ministério da Educação em 24 de junho de 2015, as Diretrizes Curriculares Nacionais para a formação inicial e continuada dos profissionais do magistério da educação básica, a Medida Provisória n. 746 de 22 de setembro de 2016 e o documento base do PPE.

A partir desse estudo inicial, dos marcos legais, foi construída a discussão com o documento base do PPE, com o foco na formação continuada de professores. A análise dos marcos legais da educação brasileira sobre formação continuada de professores suscitou as considerações de autores como Saviani (2011), Ricci (2007), Dourado (2015) e Manfredi (2003), Frigotto (2016) além dos autores que tratam dos saberes docentes, Gauthier (1998) e Tardif (2002) e da formação de professores para EPT, Machado (2008), Pacheco (2008), Moura (2008/2010). Para a compreensão da evasão e retenção na educação profissional e tecnológica utilizou-se os autores como Dore e Luscher (2011) Dore et. al (2014), Cravo (2012), Machado e Moreira (2012), Kuenzer (2010) e Quartiero, et. al (2010). 
Este estudo não pretende esgotar a complexidade da legislação educacional no que se refere à formação continuada de professores na Educação Profissional, nem tão pouco trazer a totalidade do universo de estudiosos sobre os temas abordados, porém tem a pretensão de problematizar a complexidade que envolve os temas da pesquisa, contextualizando com uma política institucional adotada pelo IF analisado, para a diminuição dos índices de evasão e retenção.

\section{OS MARCOS LEGAIS E A FORMAÇÃO CONTINUADA DE PROFESSORES EM EDUCAÇÃO PROFISSIONAL}

Este estudo busca entender, em um primeiro momento, nos marcos legais da educação nacional, o que está estabelecido nesta legislação ao que se refere à educação continuada de professores. Para atingir este objetivo foram analisadas as Diretrizes e Bases da Educação (LDB) Lei 9394/96 de 20 de dezembro de 1996, Lei 12.056 de 04 de abril de 2009 - Acrescenta parágrafos ao art. 62 da Lei n 9.394, de 20 de dezembro de 1996, que estabelece as diretrizes e bases da educação nacional, a Lei 12.061, de 04 de abril de 2013 - Altera a Lei no 9.394, de 20 de dezembro de 1996, para dispor sobre a formação dos profissionais da educação e dar outras providências, o Plano Nacional de Educação Lei 13.005 de 20 de junho de 2014, o Parecer CNE/CP 02/2015, homologado pelo Ministério da Educação em 24 de junho de 2015 Diretrizes Curriculares Nacionais para a formação inicial e continuada dos profissionais do magistério da educação básica, a Medida Provisória $\mathrm{n}$. 746 de 22 de setembro de 2016 e o documento base do PPE.

Ao analisar o texto da LDB é preciso atentar para O Título VI - Dos profissionais da Educação. Este título estende-se, do artigo $61^{\circ}$ ao $67^{\circ}$, dentre os quais buscou-se a referência sobre à formação continuada de professores. Destaca-se o artigo 62 nos parágrafos $1^{\circ} \mathrm{e} 2^{\circ}$, o artigo 63 no parágrafo $3^{\circ} \mathrm{e} o$ artigo 67 no parágrafo $2^{\circ}$, que definem:

Artigo 62, $\S 1^{\circ}$ A União, o Distrito Federal, os Estados e os Municípios, em regime de colaboração, deverão promover a formação inicial, a continuada e a capacitação dos profissionais de magistério. (Incluído pela Lei $n^{\circ} 12.056$, de 2009).

$\S 2^{\circ}$ A formação continuada e a capacitação dos profissionais de magistério poderão utilizar recursos e tecnologias de educação à distância. (Incluído pela Lei no 12.056, de 2009).

Artigo 63: III-programas de educação continuada para os profissionais de educação dos diversos níveis.

Artigo 67: II - aperfeiçoamento profissional continuado, inclusive com licenciamento periódico remunerado para esse fim (LDB, p. 22).

Considera-se que com relação à formação continuada docente para a educação básica o que o texto da LDB apresenta de novo é a introdução do ensino a distância para a formação continuada, porém esta é utilizada de modo a abarcar todos os profissionais do magistério.

Observa-se que no artigo $62^{\circ}$ a formação é entendida como capacitação em serviço e no artigo $67^{\circ}$ o termo de referência utilizado foi aperfeiçoamento profissional, assim sendo é possível entender que não há uma definição única para a formação continuada docente estabelecida nesta lei tal como no texto anterior da LDB. Analisando a versão original da LDB no que se refere a formação continuada docente, Ricci (2007) considera que existe um hibridismo que revela concepções distintas ou antagônicas. 
Esse hibridismo parece ser uma tônica nos debates e reflexões sobre formação de professores. Treinamento, formação em serviço, aperfeiçoamento profissional, capacitação e formação continuada são alguns termos que acabam por revelar as concepções norteadoras de textos, propostas ou políticas educacionais (RICCI, 2007, p. 167).

Analisando os pressupostos defendidos por Ricci (2007) e buscando compreender o contexto de construção da LDB, é possível remeter aos embates de concepções que marcaram os debates e construções de projetos distintos anteriores a construção do texto da LDB, conforme aponta Manfredi (2003).

Quanto ao Plano Nacional de Educação, está previsto no artigo n 214 da Constituição Federal e tem vigência de dez anos, estabelecendo diretrizes com metas e estratégias para a educação nacional, sendo que os Estados da Federação e cada Município deve ter seu plano considerando o Plano Nacional de Educação Vigente. Este se apresenta na forma da Lei $n^{\circ} 13.005$ de junho de 2014. Este plano é válido do ano de 2014 até o ano 2024 e apresenta dez diretrizes e vinte metas com suas estratégias. A Meta 16 trata da formação continuada de professores, define:

Meta 16: formar, em nível de pós-graduação, 50\% (cinqüenta por cento) dos professores da educação básica, até o último ano de vigência deste PNE, e garantir a todos (as) os(as) profissionais de educação básica formação continuada em sua área de atuação, considerando as necessidades, demandas e contextualizações dos sistemas de ensino (Lei 13.005/14, p. 13).

Considera-se que o arranjo posto no PNE deve vir a colaborar para uma melhoria qualitativa na formação continuada docente, conforme aponta a Meta 16, acima citada, somada a Meta 17, a qual trata da valorização do magistério .

Conforme apontado por Saviani (2011) é impossível equacionar o problema da formação de professores sem enfrentar simultaneamente a questão das condições do trabalho docente, pois estes aspectos andam juntos. A relação entre uma boa formação e o exercício do trabalho satisfatório é diretamente estabelecida.

Ao analisar o PNE 2014-2024, Dourado (2015) considera que a sua aprovação inaugura uma nova fase para as políticas educacionais brasileiras. Esta política sinaliza com suas diretrizes, metas e estratégias a busca da maior organicidade para a educação nacional.

O Ministério da Educação homologou o Parecer CNE/CP 02/2015 em 09/06/2015, neste constam as novas Diretrizes Curriculares Nacionais para a Formação Inicial e Continuada dos Profissionais do Magistério da Educação Básica. Sobre a construção das novas diretrizes curriculares salienta Dourado (2015) que a formação de profissionais do magistério da educação básica é constituída de diferentes concepções em disputa, porém o que é reiterado em resultados de estudos é a necessidade de repensar a formação desses profissionais.

O Parecer CNE/CP 02/2015, considera:

A formação continuada compreende dimensões coletivas, organizacionais e profissionais, bem como o repensar do processo pedagógico, dos saberes e valores, e envolve atividades de extensão, grupos de estudos, reuniões pedagógicas, cursos, programas e ações para além da formação mínima exigida ao exercício do magistério 
da educação básica, tendo como principal finalidade a reflexão sobre a prática educacional e a busca de aperfeiçoamento técnico, pedagógico, ético e político do profissional docente (Parecer CNE/CP 02/2015, 2015, p.34).

Entende-se que o documento sinaliza a construção de um perfil de professor reflexivo apto a repensar o processo pedagógico e em constante busca de aperfeiçoamento. As novas DCNs consideram a necessidade de articular as Diretrizes curriculares Nacionais para a formação de inicial e continuada, em nível superior e as diretrizes curriculares nacionais para a educação básica, buscando por maior organicidade das políticas educacionais.

Na busca por maior organicidade das políticas, as novas DCNs enfatizam que estes processos implicam o repensar e o avançar nos marcos referenciais atuais para a formação inicial e continuada por meio de ações mais orgânicas entre as políticas e a gestão para a educação básica e a educação superior, incluindo a pós-graduação e, nesse contexto, para as políticas direcionadas à valorização do magistério (DOURADO, 2015, p. 306).

Assim sendo a busca por maior organicidade entre as políticas entre educação básica e educação superior tende, em análise preliminar, a contribuir para a redução do abismo existente entre ambas e reduzir seus impactos na formação continuada docente. Somado a este contexto a importante questão da valorização do magistério nos remete ao que destaca Saviani (2011), quando afirma ser imprescindível pensar a formação docente associada à valorização do magistério.

A complexidade desse tema, formação de professores, é estudada por vários autores que se propõem a pensar a temática levando em consideração os diversos aspectos que envolvem a formação docente. Para entender a formação de professores é preciso compreender quais saberes fazem parte da profissão docente.

Dentre os autores que trabalham a formação docente, um deles é o francês Clermont Gauthier (1998), que parte do pressuposto de que é necessário definir um repertório de conhecimentos próprios ao ensino. Ele afirma que todas as profissões têm esclarecidos os saberes que lhe são próprios, porém com os saberes docentes, isso não acontece.

Gauthier alerta para o fato de que existem ideias preconcebidas no que se refere ao saberes docentes, tais como: basta conhecer o conteúdo, basta ter talento, basta ter bom senso, basta seguir a intuição, basta ter conhecimento ou basta ter cultura. Estas ideias dificultam a definição de um repertório de conhecimentos próprios do ensino. 0 autor afirma ainda:

De fato, é muito mais pertinente conceber o ensino como a mobilização de vários saberes que formam uma espécie de reservatório no qual o professor se abastece para responder a exigências específicas de sua situação concreta de ensino (GAUTHIER, 1998, p. 28).

Dentre os vários saberes mobilizados pelo professor no ato educativo, Gauthier (1998) privilegia o saber da ação pedagógica. Há um paradoxo no que se refere à prática docente e o necessário para tal prática, conforme salienta o autor:

Os saberes da ação pedagógica legitimado pelas pesquisas são atualmente o tipo de saber menos desenvolvido no reservatório de saberes do professor, e também, paradoxalmente, o mais necessário a profissionalização (GAUTHIER, 1998, p. 34). 
Para Tardif (2002) os saberes dos professores são oriundos do meio social. A perspectiva do autor busca situar os saberes do professor na relação entre o individual e o social, como "um modelo construído a partir das categorias dos próprios docentes e dos saberes que utilizam efetivamente em sua prática profissional” (TARDIF, 2002, p. 18).

Tardif (2002) propõe que os saberes devem estar conectados ao cotidiano escolar, numa relação com os outros atores que fazem parte de uma instituição concreta. A partir disso, os saberes docentes, devem fazer parte de um contexto de sala de aula, na relação professor e estudante e com a história pessoal e profissional do professor.

Pensar os saberes docentes é refletir também sobre a formação desses profissionais. Tardif (2002) salienta que é necessário repensar a formação de professores, partindo do cotidiano, de um determinado contexto de atuação. A formação de professores deve buscar a equiparação entre o conhecimento produzido nas universidades, com o desenvolvido a partir da prática na sala de aula.

Neste vasto e complexo tema que é a formação de professores, atentando para a realidade da formação de professores que atuam em educação profissional e tecnológica, tem-se que considerar a peculiaridade desta modalidade de ensino na atualidade. Para isso é necessário refletir a proposição de alguns autores sobre a EPT.

Pacheco (2008), um dos autores que pensa a formação de professores para EPT, faz referência a construção das políticas públicas para essa forma de educação e um dos eixos contemplados é a formação de professores. 0 autor salienta que a formação será em caráter inicial e continuado. Pacheco (2008) enfatiza que é essencial a oferta de Licenciaturas para a EPT, além de curso de pós-graduação Lato Sensu e Stricto Sensu. Mesmo que o avanço da qualificação dos professores tenha crescido é ainda necessário formas de cooperação entre outros segmentos para a expansão da rede federal de educação profissional e tecnológica.

Outro ponto de reflexão é a complexidade da formação profissional e tecnológica e do ensino médio integrado. Moura (2010) aponta que ainda há divergência entre as práticas pedagógicas e os modelos culturais dos estudantes. Isso é possível perceber quando o fracasso escolar e a evasão estão presentes no contexto escolar. 0 autor ainda acrescenta quais são as principais dificuldades presentes nesse contexto:

Dentre as dificuldades que afloram diretamente nas escolas, mas cujas origens estão muito mais na estrutura da sociedade e nos próprios sistemas de ensino do que nelas, merecem destaques as questões relacionadas ao financiamento, à gestão desses sistemas e das escolas especificamente, à formação inicial e continuada de professores, assim como o déficit quantitativo dos profissionais da educação; às concepções educacionais e às práticas pedagógicas, e à infraestrutura física, dentre outros aspectos (MOURA, 2010, p. 59 grifo nosso).

Machado (2008) aponta para os desafios que são inerentes aos professores da EPT.

Os professores da educação profissional enfrentam novos desafios relacionados às mudanças organizacionais que afetam as relações profissionais, aos efeitos das inovações tecnológicas sobre as atividades de trabalho e culturas profissionais, ao novo papel que os sistemas simbólicos desempenham na estruturação do mundo do trabalho, ao aumento das exigências de qualidade na produção e nos 
serviços, à exigência de maior atenção à justiça social, às questões éticas e de sustentabilidade ambiental. São novas demandas à construção e reestruturação dos saberes e conhecimentos fundamentais à análise, reflexão e intervenção críticas e criativas na atividade de trabalho (MACHADO, 2008, p. 15).

O professor da rede federal da educação profissional e tecnológica tem o desafio de ensinar seus estudantes para que eles compreendam o mundo do trabalho de forma crítica e reflexiva e saibam qual o papel dos avanços tecnológicos para a sociedade atual. É necessário o aprendizado histórico, social, político e econômico do qual os saberes são originados. Com essas vivências e experiências será possível que o estudante da educação profissional e tecnológica, possa ler, interpretar e atuar neste mundo capitalista (MACHADO, 2008).

Sobre a dificuldade em relação à metodologia adotada pelo professor, Machado (2008) salienta que é importante que o professor desenvolva a habilidade de usar diferentes formas de ensinar dependendo do conteúdo abordado. Isso porque a especificidade da demanda atendida pela educação profissional é oriunda de diferentes contextos econômicos, sociais e culturais.

Sobre qual formação, a educação profissional e tecnológica busca, Moura (2008) diz que é preciso compreender o estudante como ativo no processo de ensino-aprendizagem, capaz de construir seu próprio conhecimento e assim assumir a capacidade de pensar sobre sua própria formação.

Em contrapartida, outro movimento das políticas educacionais para a formação de professores na Educação Profissional, ganhou destaque no final do ano de 2016. Nesse ano foi publicada a Medida Provisória n. 746, de 22 de setembro, na qual reformula o currículo do Ensino Médio. Dentre várias alterações, uma delas influenciará diretamente a formação de professores para a Educação Profissional, como segue no inciso IV, do artigo n. 61, reforçando os profissionais que poderão ministrar aulas para os cursos técnicos:

IV- profissionais com notório saber reconhecidos pelos respectivos sistemas de ensino para ministrar conteúdos de áreas afins à sua formação para atender o dispositivo no inciso $V$ do caput do art. 36.

Assim, profissionais com reconhecidos conhecimentos sobre as áreas técnicas ou profissionais poderão ministrar aulas nos cursos técnicos e profissionais, como um dos itinerários formativos possíveis, sem mesmo possuírem uma formação pedagógica para tal. Os itinerários formativos escondem uma antiga segregação da educação profissional e da educação básica, reafirmando a educação oferecida à classe trabalhadora. Conforme salienta Frigotto (2016)

Neste sentido é uma reforma que anula Lei No 1.821 de 12 de março de 1953. Que dispõe sobre o regime de equivalência dos cursos de grau médio para efeito de matrícula nos curso superiores e cria novamente, com outra nomenclatura, o direcionamento compulsório à universidade. Um direcionamento que camufla o fato de que para a maioria da classe trabalhadora seu destino são as carreiras de menor prestigio social e de valor econômico (FRIGOTTO, 2016, p. 2). 
Nesse sentido, a reformulação do currículo do Ensino Médio deixa clara a separação legalizada que reafirma a educação precária destinada à classe trabalhadora. (FRIGOTTO, 2016). E mais uma vez esconde os legados destrutivos que essa medida deixará para as novas gerações de trabalhadores, além de deturpar e esconder uma realidade construída pelos Institutos Federais.

Os impactos dessas políticas serão sentidas e vividas pelos estudantes da Rede de Educação Profissional, tornando-se ainda mais complexa a relação entre a formação de professores e a evasão e retenção.

\section{A EVASÃO E A RETENÇÃo NO CONTEXTO DA EDUCAÇÃO PROFISSIONAL E TECNOLÓGICA}

A problemática da evasão e retenção na educação profissional e tecnológica tornou-se alvo de estudos e intervenções num passado recente. Isso faz com que pesquisas e estratégias de intervenção para combater a evasão, sejam pioneiras nesse contexto. Esse cenário aponta para uma complexidade ainda pouco apropriada pelas pesquisas, incidindo numa continuidade de exclusão social. (DORE e LUSCHER, 2011; CRAVO, 2012; MACHADO e MOREIRA, 2012).

Assim as temáticas da evasão e retenção ocupam um espaço de preocupação no cenário das políticas públicas educacionais, visto que várias ações são implementadas para minimizar os seus efeitos. Uma dessas ações, produzidas num Instituto Federal de Educação, Ciência e Tecnologia, refere-se a um conjunto de estratégias e ações para o combate à evasão e retenção, nomeado de Programa Permanência e Êxito (PPE).

O Programa Permanência e Êxito foi criado no instituto pesquisado como uma proposta de intervenção institucional ao problema da evasão e retenção. Um dos fatores motivadores refere-se ao Acórdão do TCU Nº 506/2013 de 13 de março 2013, do qual aponta índices elevados de evasão e retenção na Rede Federal de Educação Profissional e Tecnológica (RFEPT). Esse documento elaborado pelo TCU recomenda a Secretaria de Educação Profissional e Tecnológica (SETEC) o desenvolvimento de ações a fim de minimizar esses efeitos negativos para a qualidade da educação profissional e tecnológica.

A atenção do TCU é em virtude de uma grande expansão da Rede Federal, a partir de 2008 e consequente grande investimento financeiro dos cofres públicos. Os índices apontados pelo TCU (2013) indicam a taxa de evasão na educação básica de $24 \%$ no técnico integrado na modalidade PROEJA e na educação superior, a taxa das licenciaturas é de 8,70\%, apontando o maior índice nessa categoria de ensino. Os índices de retenção são ainda maiores, na educação básica, a primeira posição é do curso técnico subseqüente, com 49,34\%. No nível superior, o índice de 68,09\% de retenção é dos cursos bacharelados.

A evasão escolar é compreendida como "um fenômeno complexo, multifacetado e multicausal, atrelado a fatores pessoais, sociais e institucionais, que podem resultar na saída pro-visória do aluno da escola ou na sua saída definitiva do sistema de ensino" (DORE, et al., 2014, p. 386). Ou seja, as variáveis envolvidas na produção da evasão são tão complexas que a análise de causa e efeito torna-se frágil para explicar tal fenômeno.

E ainda de acordo com Dore e Luscher (2011), as causas da evasão são multifatoriais, ou seja, as relações entre escola, família, comunidade e mundo do trabalho são enunciadores de evasão escolar. 0 momento de decisão de sair de escola é consequência de uma trajetória de exclusão e fracasso que tem como resultado a evasão. Nesse percurso o aluno apresenta sinais e comportamentos de risco, sendo essencial ao trabalho pedagógico captar esses sinais enviados pelos estudantes. As causas da evasão adotadas como norteadoras do trabalho do PPE foram categorizadas como fatores individuais, fatores internos e externos à instituição. 
0 processo de inclusão no modo de produção capitalista se refere a uma inclusão subordinada, de acordo com Kuenzer (2010). Isso quer dizer que é preciso compreender a política pública profissional num contexto capitalista, que almeja a ampliação dos níveis de escolarização formal aos trabalhadores e assim a democratização do conhecimento as classes trabalhadoras, compreendendo o trabalho numa perspectiva de humanização (KUENZER, 2010; QUARTIERO, et. al 2010).

Nesse sentido, ao refletir sobre ao modelo social e econômico do qual impera na sociedade atual, o capitalismo, faz-se necessário compreender como a política pública é efetiva em seus contextos. Na sequência serão apresentadas reflexões sobre o PPE e as ações voltadas à formação de professores.

\section{A FORMAÇÃO DOCENTE NO PROGRAMA PERMANÊNCIA E ÊXITO}

Somente o acesso à educação não garante a permanência e êxito dos sujeitos na escola, é necessário o entrelaçamento de políticas educacionais para que os estudantes superem a visão de trabalho alienante. Pois somente quando os índices de evasão e retenção forem combatidos ativamente pelas instituições de ensino é que será possível maximizar os resultados das políticas educacionais para a educação profissional e tecnológica.

Nesse sentido todas as ações do PPE visam proporcionar uma melhora na qualidade do ensino oferecido, principalmente refletido em permanência e êxito dos estudantes. No quadro 1 é apresentado as ações específicas à formação continuada de professores.

\begin{tabular}{|c|c|c|c|c|}
\hline $\begin{array}{lr}\text { Causas } & \text { da } \\
\text { Evasão } & \text { e } \\
\text { Retenção } & \end{array}$ & $\begin{array}{l}\text { Estratégias } \\
\text { para a } \\
\text { Permanência e } \\
\text { Êxito }\end{array}$ & Ações & Período & Responsáveis \\
\hline $\begin{array}{l}\text { a. Falta de } \\
\text { Formação } \\
\text { continuada } \\
\text { dos } \\
\text { servidores } \\
\text { b. Dificuldade } \\
\text { com } \\
\text { metodologia } \\
\text { s adotadas } \\
\text { pelos }\end{array}$ & $\begin{array}{l}\text { 1. Programa } \\
\text { Institucional de } \\
\text { formação } \\
\text { continuada dos } \\
\text { servidores } \\
\text { diretamente } \\
\text { ligados ao } \\
\text { ensino }\end{array}$ & $\begin{array}{l}\text { Reuniões } \\
\text { pedagógicas de } \\
\text { planejamento } \\
\text { dos cursos } \\
\text { - Efetivar as } \\
\text { possibilidades } \\
\text { das áreas de } \\
\text { integração } \\
\text { previstas nos } \\
\text { PPCs; }\end{array}$ & $\begin{array}{c}\text { Conforme } \\
\text { planejamento }\end{array}$ & $\begin{array}{l}\text { Coordenadores } \\
\text { de Curso e Eixo } \\
\text { Tecnológico } \\
\text { Setor de Apoio } \\
\text { Pedagógico }\end{array}$ \\
\hline $\begin{array}{l}\text { professores } \\
\text { (causa } \\
\text { interna) }\end{array}$ & & $\begin{array}{l}\text { - Encontros de } \\
\text { socialização de } \\
\text { boas práticas; }\end{array}$ & Bimestral & $\begin{array}{l}\text { Setor de Apoio } \\
\text { Pedagógico }\end{array}$ \\
\hline
\end{tabular}

\section{Quadro 1: Estratégias das ações do PPE}

Fonte: Programa Permanência e Êxito (2014)- Adaptado

Neste quadro são apresentados os fatores relacionados à evasão e retenção bem como as estratégias de ação do referido programa. As ações apontadas referem-se à problemática de falta de formação continuada dos servidores e dificuldade com as metodologias adotadas pelo professor em sala de aula. Essas carências e/ou dificuldades encontradas levantam a problemática sobre qual formação de professores é necessário na rede profissional e tecnológica, visto que há características peculiares. Essa peculiaridade leva muitas vezes a uma carência de teorias consistentes, bem como políticas públicas duradouras para a formação de professores para a educação profissional e tecnológica (EPT), como afırma Machado (2008). 


\section{CONSIDERAÇÕES FINAIS}

Vários são os desafios postos à formação de professores para a Educação Profissional e Tecnológica, principalmente quando esse professor não possui uma formação inicial para a docência. É primordial que a formação continuada de professores seja melhor articulada entre os próprios docentes.

Considerando que o estabelecido na LDB, mesmo com as atuais alterações, esta lei não contempla satisfatoriamente a complexidade da formação docente nas diversas modalidades de ensino. Estas considerações se estendem a formação continuada de professores, mais especificadamente no contexto do PPE.

Para que o PPE esteja em consonância com o atual PNE e com as Diretrizes Curriculares Nacionais, no que se refere à formação docente é preciso que as ações se efetivem adequadamente ao nível e modalidade de ensino que o docente atua. Considerando a diversidade dos níveis e modalidades existentes na educação profissional e tecnológica.

O contexto da EPT é parte dessa complexidade da formação de professores, isso implica conhecer e se aprofundar, nos diferentes contextos que ela se insere. Ao refletir, a natureza multifacetada do tema da evasão e retenção, as características da educação profissional e tecnológica e os saberes docentes, é importante que o próprio professor, em seu contexto, repense sua prática, utilizando a identidade e a experiência enquanto pessoa e profissional.

E essa complexidade e dificuldade poderá ser acentuada com a inexistência da garantia da formação de professores para a Educação Profissional e Tecnológica. Visto que profissionais com "notório saber", ou seja, sem a formação para serem professores, ministrarão aulas para os cursos técnicos. A reforma do Ensino Médio, proferida pela Medida Provisória n. 746/2016, reafirma mais uma vez que a educação profissional deve ser direcionada à classe trabalhadora e a educação formal ou propedêutica, destinada as classes que usam da força de trabalho de outros.

Isso porque os saberes docentes e a formação de professores estão diretamente relacionados, ou seja, pensar a formação de professores deve abarcar os saberes docentes, enquanto prática no cotidiano escolar. Além disso, a formação deve levar à reflexão de sua prática, num contexto real vivido.

O PPE articula três grandes ações que balizam a formação continuada, que são os encontros de socialização de boas práticas, a efetivação da integração curricular prevista no Projeto Político Pedagógico e reuniões para organização dos cursos. Essas ações revelam um importante instrumento para a diminuição da evasão e da retenção, no que se refere à formação de professores. Visto que, dar ênfase a formação do professor, torna-se um elemento essencial, pois revela o caráter preventivo da evasão e retenção.

Refletir sobre quais saberes fazem parte da profissão docente no contexto da EPT é essencial, pois a partir disso é possível pensar na formação continuada como caminho para qualificar a oferta da educação. Assim, a formação de professores, torna-se uma das ações que contribuem para diminuir os índices de evasão, como traz o documento do PPE. 


\section{REFERÊNCIAS}

BRASIL. Constituição (1988). Constituição da República Federativa do Brasil: promulgada em 5 de outubro de 1988: atualizada. Disponível em: <http://www.planalto.gov. br/ccivil_03/constituicao/ConstituicaoCompilado.htm> Acesso em: 27 nov. 2015.

. Decreto $n^{\circ}$ 6755, de 29 de janeiro de 2009. Institui a Política Nacional de Formação de Profissionais do Magistério da Educação Básica, disciplina a atuação da Coordenação de Aperfeiçoamento de Pessoal de Nível Superior - CAPES no fomento a programas de formação inicial e continuada, e dá outras providências. Disponível em: <http://www. planalto.gov.br/ccivil_03/_ato2007-2010/2009/decreto/d6755.htm> Acesso em: 27 nov. 2015.

Decreto $n^{\circ}$ 6094, de 24 de abril de 2007. Dispõe sobre a implementação do Plano de Metas compromisso todos pela Educação, pela União Federal, em regime de colaboração com Municípios, Distrito Federal e Estados, e a participação das famílias e da comunidade, mediante programas e ações de assistência técnica e financeira, visando a mobilização social pela melhoria da qualidade da educação básica. Disponível em: <http:// www.planalto.gov.br/ccivil_03/_ato2007-2010/2007/decreto/d6094.htm> Acesso em: 12 nov. 2015.

Lei $n^{\circ} 11.892$ de 29 de dezembro de 2008. Institui a Rede Federal de Educação Profissional, Científica e Tecnológica, cria os Institutos Federais de Educação, Ciência e Tecnologia, e dá outras providências. Disponível em: <http://www.planalto.gov.br/ccivil_03/_ ato2007-2010/2008/lei/l11892.htm> Acesso em: 27 nov. 2015.

Lei $\mathrm{n}^{\circ} 12.014$ de 06 de agosto de 2009. Altera o art. 61 da Lei no 9.394, de 20 de dezembro de 1996, com a finalidade de discriminar as categorias de trabalhadores que se devem considerar profissionais da educação. Disponível em: <http://www.planalto.gov. br/ccivil_03/_Ato2007-2010/2009/Lei/L12014.htm\#art1> Acesso em: 27 nov. 2015.

. Lei $n^{\circ} 12.796$ de 04 de abril de 2009. Altera a Lei no 9.394, de 20 de dezembro de 1996, que estabelece as diretrizes e bases da educação nacional, para dispor sobre a formação dos profissionais da educação e dar outras providências. Disponível em: <http:// www.planalto.gov.br/ccivil_03/_Ato2011-2014/2013/Lei/L12796.htm\#art1> Acesso em: 27 nov. 2015.

. Lei $n^{\circ} 13.005$ de 25 de junho de 2014. Plano Nacional de Educação. Disponível em: < http://www.planalto.gov.br/ccivil_03/_ato2011-2014/2014/lei/l13005.htm> Acesso em: 27 nov. 2015.

Lei $n^{\circ} 12.056$ de 13 de outubro de 2009. Acrescenta parágrafos ao art. 62 da Lei n' 9.394, de 20 de dezembro de 1996, que estabelece as diretrizes e bases da educação nacional. Disponível em: <http://www.planalto.gov.br/ccivil_03/_ato2007-2010/2009/lei/ I12056.htm> Acesso em: 27 nov. 2015

. Lei n 9.394, de 20 de dezembro de 1996. Lei de Diretrizes e Bases da Educação Nacional. Disponível em: <http://www.planalto.gov.br/ccivil_03/Leis/L9394.htm> Acesso em: 27 nov. 2015.

MEC. SETEC. IF FARROUPILHA. Programa Permanência e Êxito. 2014.

Medida Provisória n. 746, de 22 de setembro de 2016. Institui a Política de Fomento à Implementação de Escolas de Ensino Médio em Tempo Integral, altera a Lei $n^{\circ}$ 9.394, de 20 de dezembro de 1996, que estabelece as diretrizes e bases da educação 
nacional, e a Lei n 11.494 de 20 de junho 2007, que regulamenta o Fundo de Manutenção e Desenvolvimento da Educação Básica e de Valorização dos Profissionais da Educação, e dá outras providências. Diário Oficial da União, Brasília-DF, 2016. Disponível em: http:// www.planalto.gov.br/ccivil_03/_Ato2015-2018/2016/Mpv/mpv746.htm. Acesso em: 16 de fevereiro de 2016.

CRAVO, A. C. Análise das causas da evasão escolar do curso técnico de informática em uma faculdade de tecnologia de Florianópolis. Revista GUAL, Florianópolis, v. 5, n. 2, ago. 2012.

DORE, R. e LÜSCHER, A. Z. Permanência e evasão na educação técnica de nível médio em Minas Gerais. Cad. Pesqui.[online], vol.41, n.144, 2011.

DORE, R.; SALES, P. E. N.; CASTRO, T. L. Evasão nos cursos técnicos de nível médio da Rede Federal de Educação Profissional de Minas Gerais. In: DORE, R. (Org.). Evasão na educação: estudos, políticas e propostas de en־frentamento. Brasília: IFB, 2014. p. 379-413.

DOURADO, L.F. Diretrizes Curriculares Nacionais para Formação Inicial e Continuada dos profissionais do magistério da educação básica: concepções e Desafios. Revista Educação e Sociedade, Campinas, v.36, n. 131, abr./jun., 2015.

FRIGOTTO, G. Reforma do Ensino Médio do (DES) Governo de Turno: decreta-se uma escola para os ricos e outra para os pobres. Movimento Revista de Educação, Rio de Janeiro, ano 3, n. 5, 2016.

GAUTHIER, C. et al. Por uma teoria da Pedagogia. ljuí: Unijuí, 1998.

KUENZER, A. Z. As políticas de educação profissional: uma reflexão necessária. In.: MOLL, J. Educação profissional e tecnológica no Brasil contemporâneo: desafios, tensões e possibilidades. Porto Alegre: Artmed, 2010.

MACHADO, L. R. de S. Diferenciais inovadores na formação de professores para a educação profissional. Revista Brasileira da Educação Profissional e Tecnológica. v. 1, n. 1, jun. 2008.

MACHADO, M. R. L.; MOREIRA, P. R. Educação profissional no Brasil, evasão escolar e transição para o mundo do trabalho. In: Seminário Nacional de Educação Profissional e Tecnológica (SENEPT). Anais do Seminário. Centro Federal de Educação Tecnológica de Minas Gerais (CEFET-MG). Belo Horizonte-MG. Junho de 2010.

MANFREDI. S. M. Educação Profissional no Brasil. São Paulo: Cortez: Editora, 2002, $317 \mathrm{p}$.

MOURA, D. H. A formação de docentes para a educação profissional e tecnológica. Revista Brasileira da Educação Profissional e Tecnológica. v. 1, n. 1, jun. 2008.

D. H. Ensino médio e educação profissional: dualidade histórica e possibilidade de integração. In.: MOLL, J. Educação profissional e tecnológica no Brasil contemporâneo: desafios, tensões e possibilidades. Porto Alegre: Artmed, 2010.

PACHECO, E. SETEC/MEC: Bases para uma Política nacional de EPT (2008). Disponível em: <http://portal.mec.gov.br/setec/arquivos/pdf2/artigos_bases.pdf>Acesso em: 27 nov. 2015.

QUARTIERO, E. M.; LUNARDI, G. M.; BIANCHETTI, L. Técnica e tecnologia: aspectos conceituais e implicações educacionais. In.: MOLL, J. Educação profissional e tecnológica no Brasil contemporâneo: desafios, tensões e possibilidades. Porto Alegre: Artmed, 2010. 
RICCI, C.S. A Lei de Diretrizes e Bases da Educação Nacional e a Formação de Professores. In: Souza, João Valdir Alves (org.). Formação de Professores para a Educação Básica: Dez anos de LDB. Belo Horizonte: Autêntica, 2007.

SAVIANI, D. Formação de Professores no Brasil: Dilemas e Perspectivas. Revista Poíesis Pedagógica, v.9, N.1 jan. /jun. 2011.

TARDIF, M. Saberes Docentes e Formação Profissional. Petrópolis: Vozes, 2002. 